\title{
Omissão de nutrientes em plantas de pinhão-manso cultivadas em solução nutritiva ${ }^{1}$
}

\author{
Janini Tatiane Lima Souza Maia², Filipe Pereira Giardini Bonfim ${ }^{3}$, Rafael Eugenio Maia Guanabens ${ }^{4}$, \\ Roberto Trentin 5 , Herminia Emilia Prieto Martinez, Paulo Roberto Gomes Pereira, \\ Paulo Cézar Rezende Fontes ${ }^{6}$ \\ http://dx.doi.org/10.1590/0034-737X201461050016
}

\section{RESUMO}

O pinhão-manso (Jatropha curcas L.), pertecente à família Euphorbiaceae, é uma planta oleaginosa que tem recebido expressiva atenção para produção de biocombustível. O objetivo deste trabalho foi avaliar o efeito da deficiência de macro e micronutrientes no crescimento e estado nutricional de pinhão-manso, cultivado em solução nutritiva. O delineamento experimental utilizado foi o inteiramente casualizado, com treze tratamentos e três repetições. Os tratamentos constituíram-se de solução completa e omissão individual de cada um dos seguintes nutrientes: N, P, K, Ca, Mg, S, B, Cu, Mn, Mo, Zn ou Fe. A ordem decrescente de restrição da produção de massa de matéria seca foi $\mathrm{N}>\mathrm{Mg}>\mathrm{S}>\mathrm{K}>\mathrm{Ca}=\mathrm{P}>\mathrm{Zn}>\mathrm{B}=\mathrm{Fe}$. As omissões de $\mathrm{N}$ e de $\mathrm{P}$ foram as que mais afetaram os teores dos macronutrientes da parte aérea das plantas e os sintomas de deficiências observados foram clorose, redução do crescimento e folhas deformadas.

Palavras-chave: Jatropha curcas L., solução nutritiva, elemento faltante, Euphorbiaceae.

\section{ABSTRACT}

\section{Effects of nutrient omission on growth and chemical composition of physic nutin hydroponics cultivation}

Jatropha curcas L. belongs to the Euphorbiaceae family. It is an oleaginousplant and it has received much attention because of the production of biofuels. The objective of this study was to evaluate the nutritional status of Jatropha curcas under deficiency of macro and micronutrients in nutrient solution. The experimental design was completely randomized with thirteen treatments and three replications. The treatments consisted of a complete solution and individual omission of each of the following nutrients: $\mathrm{N}, \mathrm{P}, \mathrm{K}, \mathrm{Ca}, \mathrm{Mg}, \mathrm{S}, \mathrm{B}, \mathrm{Cu}, \mathrm{Mn}, \mathrm{Mo}, \mathrm{Zn}$ or Fe. The decreasing orderofproductionrestriction ofdry matterwas $\mathrm{N}>\mathrm{Mg}>\mathrm{S}>\mathrm{K}>\mathrm{Ca}=\mathrm{P}>\mathrm{Zn}>\mathrm{B}=\mathrm{Fe}$. Omissions of $\mathrm{N}$ and $\mathrm{P}$ affected mots the contents of macronutrients in the shoots of physic nut and the deficiency symptoms observed were chlorosis, reduced growth and deformed leaves.

Key words: Euphorbiaceae, Jatropha curcas L., missing element,nutrient solution.

\footnotetext{
Recebido para publicação em 24/08/2012 e aprovado em 10/06/2014

Trabalho realizado na disciplina Nutrição Mineral das Plantas, do Departamento de Fitotecnia da UFV.

${ }^{2}$ Bióloga, Doutora. Faculdades Unidas do Norte de Minas (FUNORTE), Avenida Osmane Barbosa, 11111, bairro JK, 39404-006, Montes Claros, Minas Gerais, Brasil.janinitatimaia@yahoo.com.br

${ }^{3}$ Engenheiro-Agrônomo, Doutor. Faculdade de Ciências Agronômicas de Botucatu, Rua José Barbosa Barros, 1780, 18610-307, Botucatu, São Paulo, Brasil. filipegirardini@ yahoo.com.br ${ }^{4}$ Engenheiro-Agrônomo, Doutor. Pós-doutorando do Departamento de Biologia Animal, Universidade Federal de Viçosa, Campus Viçosa, Avenida Peter Henry Rolfs, s/n, $36570-000$, Viçosa, Minas Gerais, Brasil. rafael.guanabens@ufv.br

${ }^{5}$ Engenheiro-Agrônomo, Doutor. Departamento de Fitotecnia, Faculdade de Agronomia Eliseu Maciel, Avenida Eliseu Maciel, s/n, 96160-000, Capão do Leão, Rio Grande do Sul, Brasil. trentin.rt@gmail.com

${ }^{6}$ Engenheiros-Agrônomos, Doutores. Departamento de Fitotecnia, Universidade Federal de Viçosa, Campus Viçosa, Avenida Peter Henry Rolfs, s/n, 36570-000, Viçosa, Minas Gerais, Brasil.herminia@ufv.br, ppereira@ufv.br,pacerefo@ufv.br
} 


\section{INTRODUÇÃO}

A maior parte da energia consumida em todo mundo é derivada de fontes não renováveis como petróleo, carvão mineral e gás natural. A produção de energia de forma alternativa tem adquirido importância significativa, no cenário mundial de crise energética (Ginwal et al., 2005). Neste contexto, os óleos vegetais utilizados como biocombustíveis contribuem com o meio ambiente, reduzindo os níveis de poluição. O pinhão-manso (Jatropha curcas L.), pertecente à família Euphorbiaceae, conhecido também como pinhãoparaguaio, purgueira, pinha-de-purga, pinhão-de-cerca, purgante-de-cavalo, figo-do-inferno e grão-de-maluco, é uma planta oleaginosa que tem recebido expressiva atenção, por causa de o óleo de suas sementes ser utilizado como biocombustível (Padilla, 2007).

O pinhão-manso pode crescer, ou ser plantado, em solos arenosos, salinos e em fissuras de rochas (Singh et al., 2007), porém, seu crescimento é limitado em solos alagados e em declividades superiores a $30^{\circ}$ (Biswas et al., 2006). A produtividade do pinhão-manso depende muito da região e da condução da cultura, variando de 100 a $8.000 \mathrm{~kg} \mathrm{ha}^{-1}$ de sementes, quando em condições de aridez (Heller, 1996), e o teor de óleo pode variar de 34 a 54\% (Quintiliano et al., 2006), porém a alta produtividade desta planta depende de solos férteis (Laviola \& Dias, 2008).

Informações sobre as necessidades nutricionais das plantas são de suma importância para se conhecer a real demanda de cada nutriente, determinando-se as quantidades corretas dos fertilizantes a serem utilizados (Braga, 1983). A diagnose por omissão, ou técnica do elemento faltante, fornece informações semiquantitativas, relacionadas com os nutrientes que podem limitar o desenvolvimento da planta (Malavolta, 1980) e, consequentemente, a produção de óleo vegetal.

O objetivo deste trabalho foi avaliar o efeito da deficiência de nutrientes no crescimento e estado nutricional de plantas de pinhão-manso, cultivadas em solução nutritiva.

\section{MATERIAL E MÉTODOS}

O experimento foi conduzido na casa de vegetação do Laboratório de Nutrição Mineral de Plantas, do Departamento de Fitotecnia da Universidade Federal de Viçosa, de setembro a novembro de 2008. A produção de mudas de pinhão-manso (Jatropha curcas L.) foi feita por meio de sementes, germinadas em bandejas com areia lavada, sem a adição de solução nutritiva. Após 15 dias, plantas que apresentaram duas folhas definitivas foram selecionadas pela uniformidade, transferidas para vasos plásticos de $8 \mathrm{~L}$ de capacidade e submetidas aos tratamentos, par- tindo-se da solução nutritiva de Hoagland \& Arnon (Resh, 2013), diluída a $1 / 4$ da concentração usual, e omitindo-se um elemento de cada vez. O delineamento experimental utilizado foi o inteiramente casualizado, com três repetições e os tratamentos foram: solução completa, omissão individual de N, P, K, Ca, Mg, S, B, Cu, Mn, Mo, Zn ou Fe, totalizando 39 parcelas. A cada sete dias os vasos eram trocados de posição.

A solução nutritiva completa apresentou a seguinte composição: $\mathrm{N}=3,75 \mathrm{mmoL}^{-1}\left(0,25 \mathrm{de} \mathrm{NH}_{4}^{+}\right) ; \mathrm{P}=0,25$ $\mathrm{mmoL}^{-1} ; \mathrm{K}=1,5 \mathrm{mmoL}^{-1} ; \mathrm{Ca}=1 \mathrm{mmoL}^{-1} ; \mathrm{Mg}=0,5$ $\mathrm{mmoL}^{-1} ; \mathrm{S} ;=0,5 \mathrm{mmoL}^{-1} ; \mathrm{B}=11,5 \mu \mathrm{moL}^{-1} ; \mathrm{Cu}=0,075$ $\mu \mathrm{moL}^{-1} ; \mathrm{Fe}=22,5 \mu \mathrm{moL}^{-1} ; \mathrm{Mn}=3,15 \mu \mathrm{moL}^{-1} ; \mathrm{Mo}=$ $0,025 \mu \mathrm{moL}^{-1} ; \mathrm{Zn}=0,325 \mu \mathrm{moL}^{-1}$. As fontes de nutrientes utilizadas foram: $\mathrm{KH}_{2} \mathrm{PO}_{4}, \mathrm{MgSO}_{4}, \mathrm{Ca}\left(\mathrm{NO}_{3}\right)_{2}, \mathrm{KNO}_{3}$, $\mathrm{NaNO}_{3}, \mathrm{CaCl}_{2}, \mathrm{KCl}, \mathrm{Ca}\left(\mathrm{H}_{2} \mathrm{PO}_{4}\right)_{2}, \mathrm{~K}_{2} \mathrm{SO}_{4}, \mathrm{Mg}\left(\mathrm{NO}_{3}\right)_{2}$, $\mathrm{FeCl}_{3}$ e $\mathrm{Na}_{2}$ EDTA. A solução nutritiva foi mantida sob aeração constante, o volume foi completado, diariamente, com água deionizada e o $\mathrm{pH}$ foi monitorado diariamente e ajustado a $5,5 \pm 0,5$, com $\mathrm{HCl} 0,1 \mathrm{~N}$ ou $\mathrm{NaOH}$ $0,1 \mathrm{~N}$. Foi realizada somente uma troca das soluções, com base no critério de $30 \%$ de redução da condutividade elétrica inicial (Braccini et al., 1999).

Trinta e nove dias, após o transplantio, as mudas foram retiradas das soluções, sendo seus principais sintomas fotografados e descritos. Foram avaliadas as seguintes características: comprimento das raízes e do caule, volume das raízes, diâmetro do caule, número de folhas, área foliar e índice SPAD da quarta folha a partir do ápice (Coelho et al., 2010), sendo as plantas, posteriormente, separadas em raiz, caule e folhas, submetidas à secagem em estufa, com circulação de ar a $70^{\circ} \mathrm{C}$, até massa constante e, assim, determinada a produção de massa de matéria seca de cada parte. Em seguida, as amostras de caule e de folhas foram juntadas e moídas. Posteriormente, uma subamostra foi submetida à digestão nítrico-perclórica, sendo o teor de $\mathrm{K}$ determinado por fotometria de emissão de chama; o de P dosado, colorimetricamente, pelo método de redução do fosfomobilidato pela vitamina $\mathrm{C}$; o de $\mathrm{S}$ por turbidimetria do sulfato e, o de $\mathrm{Ca}$ e $\mathrm{Mg}$, por espectrofotometria de absorção atômica (A O A C ,1975). Outra subamostra foi submetida à digestão sulfúrica para a análise de $\mathrm{N}$ pelo método micro-Kjeldahl.

Os dados foram submetidos à análise de variância e, as médias, comparadas pelo teste Scott-Knott, a 5\% de probabilidade, com o programa Statistical Analysis System (SAS).

\section{RESULTADOS E DISCUSSÃO}

De modo geral, e comparativamente ao tratamento completo, a omissão de nutrientes promoveu maior res- 
trição na acumulação de massa de matéria seca de raízes que na de folhas e caules. Para massa de matéria seca de raízes, as reduções variaram de 50 a $93 \%$, para os macronutrientes, e de 14 a $30 \%$, para os micronutrientes, enquanto, para massa de matéria seca de folhas, esses valores estiveram entre 53 e $92 \%$, para os macronutrientes, e não foram significativas para os micronutrientes. Já, para os caules, houve reduções de entre 28 e $88 \%$ na produção de massa de matéria seca, com a omissão de macronutrientes. Considerando-se a produção total de massa de matéria seca, a ordem de restrição foi $\mathrm{N}>\mathrm{Mg}>\mathrm{S}>\mathrm{K}>\mathrm{Ca}=\mathrm{P}>\mathrm{Zn}>\mathrm{B}=\mathrm{Fe}$. Devem-se, à baixa demanda das plantas e ao tempo de condução do experimento, os menores efeitos das omissões de micronutrientes, que, ademais, podem ter sido supridos pelas sementes e pelo substrato usado em sua germinação, em quantidades que, embora pequenas, foram suficientes para impedir efeitos mais pronunciados em 39 dias de experimentação.

As carências de nitrogênio, enxofre, fósforo e cálcio, nessa ordem, tiveram efeito marcante na área foliar total das plantas, sendo o efeito do P relacionado, principalmente, com a redução do número de folhas emitidas e, o do $\mathrm{Ca}$, com a redução da área de cada folha. As de $\mathrm{N}$ e $\mathrm{S}$ promoveram reduções em ambos, áreas individuais das folhas e número de folhas emitidas. Omissões de $\mathrm{N}, \mathrm{Mg}, \mathrm{K}$ e Ca resultaram em reduções entre 64 e $76 \%$ do volume de raízes, enquanto as omissões de $\mathrm{Mg}$ e N promoveram reduções de 67 e $41 \%$ no índice SPAD.

Os teores dos macronutrientes da parte aérea das plantas do tratamento completo apresentaram a seguinte ordem decrescente: $\mathrm{K}>\mathrm{N}>\mathrm{Mg}>\mathrm{Ca}>\mathrm{P}>\mathrm{S}$, sendo de 40,9; 30,5; 12,4; 9,4; 2,3 e $1,0 \mathrm{~g} \mathrm{~kg}^{-1}$ respectivamente. Camargo et al. (2013) obtiveram concentrações médias de 36,52; 3,05; 28,13; 6,02; 9,0 e 3,0 $\mathrm{g} \mathrm{kg}^{-1}$ de N, P, K, $\mathrm{Ca}, \mathrm{Mg}$ e $\mathrm{S}$, em folhas de mudas de pinhão manso de 60 dias, submetidas a doses de biossólido no substrato. Laviola \& Dias (2008) encontraram teores de 31,4; 2,8; 13,$7 ; 19,0 ; 4,8$ e $1,1 \mathrm{~g} \mathrm{~kg}^{-1}$ de N, P, K, Ca, Mg e S para folhas de plantas jovens de pinhão manso, conduzidas no campo, enquanto Lima et al. (2011a) obtiveram teores de 43,5; 3,2; 38,0; 4,9; 3,9 e 2,7 $\mathrm{g} \mathrm{kg}^{-1}$ de N, P, K, Ca, $\mathrm{Mg}$ e S, em folhas jovens de plantas de 3,5 anos, cultivadas no campo.

\section{Omissão de nitrogênio}

A omissão de $\mathrm{N}$ foi a que apresentou maior efeito restritivo do crescimento das plantas. A carência de $\mathrm{N}$ reduziu, significativamente, área foliar, número de folhas e massa de matéria seca de folhas; comprimento, diâmetro e massa de matéria seca do caule; comprimento do sistema radicular e massa de matéria seca de raiz, além do teor de clorofila medido pelo índice SPAD (Tabelas 1 e 2). Massa de matéria seca de raízes, massa de matéria seca de folhas e área foliar sofreram reduções da ordem de 93, 91 e 87\%, em relação às do controle. Esse resultado era esperado, já que esse elemento é requerido em grande quantidade pelas culturas agrícolas e é o mais limitante para o crescimento das plantas (Souza \& Fernandes, 2006). A síntese de proteínas e de ácidos nucleicos é comprometida pela ausência de N, o que promove redução do crescimento vegetal (Marschner, 2012). Plantas submetidas à deficiência de nitrogênio podem apresentar redução da taxa assimilatória líquida de $\mathrm{CO}_{2}$ (Evans, 1989), determinante do crescimento vegetal (Cruz et al., 2007). Além disso, o nitrogênio correlaciona-se positivamente com o teor de clorofila da folha (Schadchina \& Dmitrieva, 1995), por isso o índice SPAD foi menor para plantas sob omissão de N.

A parte aérea das plantas cultivadas em solução nutritiva completa apresentou $30,5 \mathrm{~g} \mathrm{~kg}^{-1}$ de $\mathrm{N}$ total, enquanto as deficientes apresentaram $11,6 \mathrm{~g} \mathrm{~kg}^{-1}$ do elemento. Os teores de $\mathrm{Ca}$ e $\mathrm{K}$ reduziram-se com a deficiência de N, enquanto o de P aumentou. (Tabela 3). Os menores teores de potássio e de cálcio da parte aérea poderiam ser justificados pela existência de um sistema de cotransporte cátion-ânion, que participa na absorção de nitrato, cujo funcionamento ficaria limitado em deficiência de N (Li et al., 2013), enquanto o maior teor de $\mathrm{P}$, provavelmente, seja um efeito de concentração do $\mathrm{P}$ absorvido na menor massa de matéria seca produzida.

As plantas deficientes em $\mathrm{N}$ apresentaram intensa redução do crescimento e clorose generalizada (Figura 1), que se deveu à redução de seu teor de clorofila (Malavolta et al., 1997), além de menor desenvolvimento das raízes (Figura 2). Esses resultados corroboram os obtidos por Silva et al., (2009), também, com mudas de pinhão-manso em solução nutritiva.

\section{Omissão de magnésio}

Em ordem decrescente de restrição do crescimento, à de nitrogênio seguiu-se a omissão de magnésio. As plantas submetidas a esse tratamento tiveram comprimento, volume e massa de matéria seca de raiz reduzidos significativamente. Índice SPAD, área foliar, número de folhas, massa de matéria seca de folhas, comprimento, diâmetro e massa de matéria seca do caule foram também reduzidos pela carência de $\mathrm{Mg}$ (Tabelas1 e 2). A omissão de $\mathrm{Mg}$ restringiu em maior grau a produção de massa de matéria seca de raízes $(79 \%)$, caules $(72 \%)$ e volume radicular $(71 \%)$. O magnésio foi, também, o nutriente cuja falta causou maior redução do teor de clorofila, avaliado pelo índice SPAD (67\%). O teor de $\mathrm{Mg}$ na matéria seca da parte aérea reduziu-se de $12,4 \mathrm{~g} \mathrm{~kg}^{-1}$, nas plantas do tratamento completo, para $7,5 \mathrm{~g} \mathrm{~kg}^{-1}$ nas plan- 
tas do tratamento em que o elemento foi omitido. O teor de fósforo, por sua vez, foi significativamente maior com a omissão de magnésio, o que provavelmente se deveu a um efeito de concentração (Tabela 3).

O magnésio é essencial para o desenvolvimento normal das plantas e sua deficiência limita o crescimento vegetal. Esse elemento atua na fotossíntese e em outros processos, como glicólise e via das pentoses fosfato (Epstein \& Bloom 2004, Cakmak \& Kirby, 2008, Guha \& Rao 2012). Tem papel destacado como ativador ou regulador de várias quinases, ATPases, carboxilase/ oxigenase RuBP e várias outras enzimas do metabolismo de carboidratos (Marschner, 2012; Cakmak \& Kirkby, 2008). Dessa forma, não é inesperado que sua deficiência cause redução do crescimento da parte aérea e da raiz (Yang et al., 2013; Cakmak, 2013). As concentrações de clorofila (índice SPAD) foram significativamente menores na ausência de magnésio, em virtude de esse elemento ser integrante da molécula de clorofila (Marschner, 2012).

As plantas submetidas à omissão de magnésio apresentaram clorose internerval, que evoluiu para o branqueamento, necrose das áreas branqueadas, seca e abscisão foliar. Houve, também, moderada redução da emissão de raízes (Figuras 1 e 2). Silva et al. (2009) observaram, ainda, encarquilhamento e enrolamento das folhas velhas e, antes da abscisão, as folhas passaram da coloração amarela à arroxeada, com posterior necrose nos bordos foliares.

\section{Omissão de enxofre}

A omissão de enxofre causou redução significativa em: índice SPAD, área foliar, número de folhas e massa de matéria seca de folhas; comprimento e massa de matéria seca do caule; comprimento, volume e massa de matéria seca de raízes (Tabelas1 e 2). A restrição no su- primento de enxofre teve efeito mais severo na produção de massa de matéria seca de folhas $(72 \%$ de redução), área foliar (69\% de redução) e massa de matéria seca de raízes (64\% de redução). Sob omissão, sua concentração na matéria seca da parte aérea reduziu-se à metade, ou seja, caiu de $1,0 \mathrm{~g} \mathrm{~kg}^{-1}$ para $0,5 \mathrm{~g} \mathrm{~kg}^{-1}$. Houve efeito de concentração do teor de fósforo, que foi maior na ausência de enxofre (Tabela 3).

$\mathrm{Na}$ ausência de enxofre, geralmente, o crescimento da parte aérea é mais afetado do que o crescimento das raízes (Marschner, 2012). O enxofre participa de aminoácidos essenciais e sua deficiência interrompe a síntese de proteínas e açúcares, ocorre também acúmulo de N-orgânico e $\mathrm{N}^{-\mathrm{NO}_{3}}$, resultando em plantas de menor tamanho e número de folhas (Malavolta, 1980,) fato observado neste trabalho.

Tabela 2. Valores médios de índice SPAD (SPAD), massa de matéria seca de folhas (MSF), caules (MSC) e raízes (MSR) de mudas de pinhão-manso sob omissão de macro e micronutrientes

\begin{tabular}{lcccc}
\hline Tratamento & MSF (g) & MSC (g) & MSR (g) & SPAD \\
\hline Completo & $5,8 \mathrm{~A}$ & $3,2 \mathrm{~A}$ & $1,4 \mathrm{~A}$ & $36,07 \mathrm{~A}$ \\
$-\mathrm{N}$ & $0,5 \mathrm{~B}$ & $0,6 \mathrm{C}$ & $0,1 \mathrm{C}$ & $21,17 \mathrm{~B}$ \\
$-\mathrm{P}$ & $2,4 \mathrm{~B}$ & $2,3 \mathrm{~B}$ & $0,7 \mathrm{C}$ & $34,63 \mathrm{~A}$ \\
$-\mathrm{K}$ & $1,9 \mathrm{~B}$ & $1,9 \mathrm{~B}$ & $0,4 \mathrm{C}$ & $33,17 \mathrm{~A}$ \\
$-\mathrm{Ca}$ & $2,7 \mathrm{~B}$ & $2,0 \mathrm{~B}$ & $0,6 \mathrm{C}$ & $36,33 \mathrm{~A}$ \\
$-\mathrm{Mg}$ & $2,6 \mathrm{~B}$ & $0,9 \mathrm{C}$ & $0,3 \mathrm{C}$ & $11,73 \mathrm{C}$ \\
$-\mathrm{S}$ & $1,6 \mathrm{~B}$ & $1,8 \mathrm{~B}$ & $0,5 \mathrm{C}$ & $23,57 \mathrm{~B}$ \\
$-\mathrm{B}$ & $4,9 \mathrm{~A}$ & $3,1 \mathrm{~A}$ & $1,0 \mathrm{~B}$ & $36,67 \mathrm{~A}$ \\
$-\mathrm{Cu}$ & $5,7 \mathrm{~A}$ & $3,8 \mathrm{~A}$ & $1,6 \mathrm{~A}$ & $39,07 \mathrm{~A}$ \\
$-\mathrm{Mn}$ & $6,5 \mathrm{~A}$ & $4,8 \mathrm{~A}$ & $1,6 \mathrm{~A}$ & $35,55 \mathrm{~A}$ \\
$-\mathrm{Mo}$ & $6,5 \mathrm{~A}$ & $3,7 \mathrm{~A}$ & $1,9 \mathrm{~A}$ & $36,67 \mathrm{~A}$ \\
$-\mathrm{Zn}$ & $4,5 \mathrm{~A}$ & $2,3 \mathrm{~B}$ & $1,0 \mathrm{~B}$ & $36,00 \mathrm{~A}$ \\
$-\mathrm{Fe}$ & $4,8 \mathrm{~A}$ & $2,9 \mathrm{~A}$ & $1,2 \mathrm{~B}$ & $32,10 \mathrm{~A}$ \\
\hline
\end{tabular}

Médias seguidas de mesma letra na coluna não diferem entre si pelo teste Scott-Knott a $5 \%$ de probabilidade.

Tabela 1. Valores médios de área foliar (AF), número de folhas (NF) comprimento do caule (CC), diâmetro do caule (DC), comprimento do sistema radicular (R) e volume do sistema radicular (VR) de mudas de pinhão-manso sob omissão de macro e micronutrientes

\begin{tabular}{lrrrrrr}
\hline Tratamento & $\mathbf{A F}\left(\mathbf{c m}^{2}\right)$ & $\mathbf{N F}$ & $\mathbf{C C}(\mathbf{c m})$ & $\mathbf{D C}(\mathbf{m m})$ & $\mathbf{C R}(\mathbf{c m})$ & $\mathbf{V R}\left(\mathbf{c m}^{3}\right)$ \\
\hline Completo & $1285 \mathrm{~A}$ & $14,00 \mathrm{~A}$ & $30,67 \mathrm{~A}$ & $0,5 \mathrm{~A}$ & $36,87 \mathrm{~A}$ & $14,0 \mathrm{~A}$ \\
$-\mathrm{N}$ & $169 \mathrm{~B}$ & $4,33 \mathrm{~B}$ & $13,23 \mathrm{C}$ & $0,3 \mathrm{~B}$ & $21,95 \mathrm{~B}$ & $3,3 \mathrm{~B}$ \\
$-\mathrm{P}$ & $492 \mathrm{~B}$ & $6,67 \mathrm{~B}$ & $18,83 \mathrm{C}$ & $0,5 \mathrm{~A}$ & $31,70 \mathrm{~B}$ & $7,7 \mathrm{~B}$ \\
$-\mathrm{K}$ & $535 \mathrm{~B}$ & $7,33 \mathrm{~B}$ & $18,50 \mathrm{C}$ & $0,4 \mathrm{~B}$ & $36,83 \mathrm{~A}$ & $4,3 \mathrm{~B}$ \\
$-\mathrm{Ca}$ & $479 \mathrm{~B}$ & $9,33 \mathrm{~B}$ & $24,33 \mathrm{~B}$ & $0,5 \mathrm{~A}$ & $29,17 \mathrm{~B}$ & $5,0 \mathrm{~B}$ \\
$-\mathrm{Mg}$ & $581 \mathrm{~B}$ & $8,33 \mathrm{~B}$ & $20,83 \mathrm{C}$ & $0,4 \mathrm{~B}$ & $25,90 \mathrm{~B}$ & $4,0 \mathrm{~B}$ \\
$-\mathrm{S}$ & $404 \mathrm{~B}$ & $7,67 \mathrm{~B}$ & $24,50 \mathrm{~B}$ & $0,5 \mathrm{~A}$ & $30,17 \mathrm{~B}$ & $6,7 \mathrm{~B}$ \\
$-\mathrm{B}$ & $1089 \mathrm{~A}$ & $10,00 \mathrm{~B}$ & $30,00 \mathrm{~A}$ & $0,5 \mathrm{~A}$ & $40,17 \mathrm{~A}$ & $8,7 \mathrm{~B}$ \\
$-\mathrm{Cu}$ & $1293 \mathrm{~A}$ & $12,33 \mathrm{~A}$ & $33,83 \mathrm{~A}$ & $0,5 \mathrm{~A}$ & $37,93 \mathrm{~A}$ & $16,7 \mathrm{~A}$ \\
$-\mathrm{Mn}$ & $1506 \mathrm{~A}$ & $15,50 \mathrm{~A}$ & $33,00 \mathrm{~A}$ & $0,5 \mathrm{~A}$ & $32,00 \mathrm{~B}$ & $20,0 \mathrm{~A}$ \\
$-\mathrm{Mo}$ & $1464 \mathrm{~A}$ & $15,67 \mathrm{~A}$ & $32,50 \mathrm{~A}$ & $0,5 \mathrm{~A}$ & $46,17 \mathrm{~A}$ & $21,3 \mathrm{~A}$ \\
$-\mathrm{Zn}$ & $1083 \mathrm{~A}$ & $11,00 \mathrm{~B}$ & $25,93 \mathrm{~B}$ & $0,5 \mathrm{~A}$ & $39,63 \mathrm{~A}$ & $12,0 \mathrm{~A}$ \\
$-\mathrm{Fe}$ & $1347 \mathrm{~A}$ & $14,67 \mathrm{~A}$ & $31,67 \mathrm{~A}$ & $0,5 \mathrm{~A}$ & $38,07 \mathrm{~A}$ & $13,0 \mathrm{~A}$ \\
\hline
\end{tabular}

Médias seguidas de mesma letra na coluna não diferem entre si pelo teste Scott-Knott a 5\% de probabilidade. 
A ausência de enxofre provocou redução do crescimento das plantas, acompanhada de clorose generalizada, principalmente nas folhas novas, corroborando os resultados encontrados por Silva et al. (2009) e Lavres Junior et al. (2009). O sistema radicular também foi bastante comprometido pela omissão de enxofre neste experimento (Figuras 1 e 2).

\section{Omissão de potássio}

A omissão de potássio reduziu a área foliar, o número de folhas e a massa de matéria seca de folhas; o comprimento, o diâmetro e a massa de matéria seca do caule; o volume e a massa de matéria seca de raízes (Tabelas 1 e 2). Comparativamente ao tratamento com-

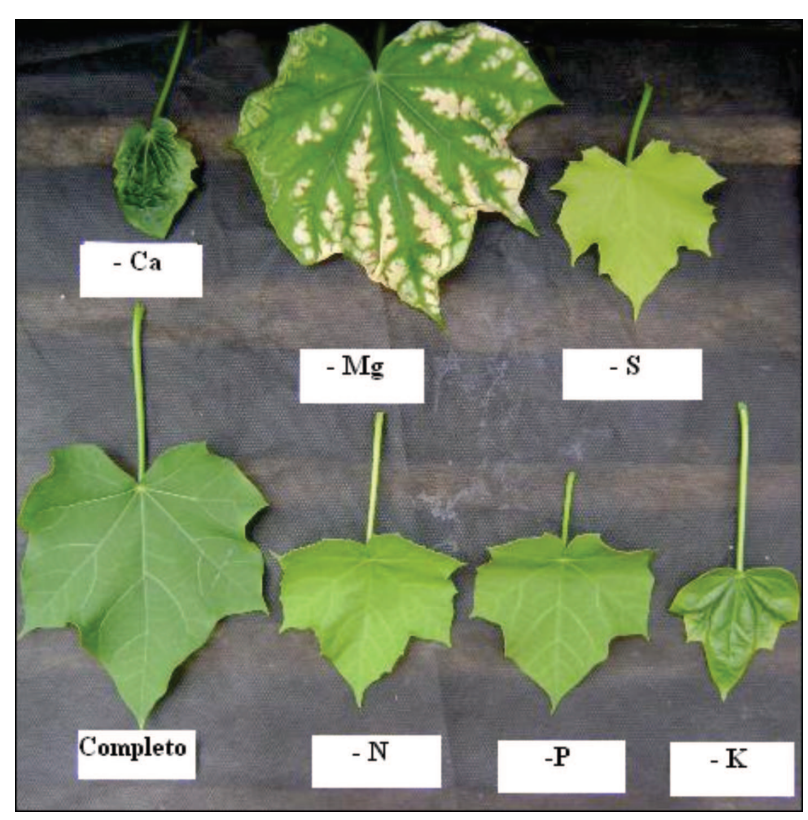

Figura 1. Sintomas visuais de deficiência de macronutrientes em folhas de mudas de pinhão-manso. pleto, a omissão de $\mathrm{K}$ teve efeitos mais acentuados na produção de massa de matéria seca ( $71 \%$ de redução) e no volume de raízes (69\% de redução), vindo, em seguida, a redução da produção de massa de matéria seca de folhas, que foi $67 \%$ menor. A concentração de $\mathrm{K}$ na matéria seca da parte aérea reduziu-se de 40,9 g $\mathrm{kg}^{-1}$ para 9,6 $\mathrm{g} \mathrm{kg}^{-1}$, enquanto nessa mesma condição, por causa do efeito de concentração, $\mathrm{P}$ e $\mathrm{Mg}$ tiveram suas concentrações aumentadas (Tabela 3 ). Em virtude de o $\mathrm{K}$ ser requerido em grandes quantidades pelas plantas, (Niu et al., 2013), a redução do crescimento da parte aérea e das raízes em sua ausência era esperada. O nutriente está envolvido nos processos de osmorregulação, extensão celular, abertura e fechamento de estômatos, ativação de enzimas, sínteses de proteínas (Marschner, 2012; Pettigrew, 2008), entre outros.

Nas plantas submetidas à ausência de K, foram observados clorose, que se iniciou nos bordos e foi mais acentuada em folhas velhas, encarquilhamento das folhas e redução da emissão de raízes (Figuras 1 e 2). Os sintomas observados foram semelhantes aos encontrados por Silva et al. (2009) com pinhão-manso e por Barroso et al. (2005) com mudas de teca (Tectona grandis Linn. F.).

\section{Omissão de fósforo}

A omissão de Fósforo afetou área foliar, número de folhas e massa de matéria seca de folhas; comprimento e massa de matéria seca do caule; comprimento, volume e massa de matéria seca de raízes (Tabelas 1 e 2). Houve redução do número de folhas (52\%), área foliar $(62 \%)$ e produção de massa de matéria seca de folhas $(59 \%)$. A concentração na parte aérea reduziuse de 2,3 para $1,1 \mathrm{~g} \mathrm{~kg}^{-1}$. As concentrações de $\mathrm{K}, \mathrm{Ca}, \mathrm{S}$ e $\mathrm{N}$ na parte aérea também se reduziram com a omissão de P (Tabela 3).

Tabela 3. Teor de macronutrientes $\left(\mathrm{g} \mathrm{kg}^{-1}\right)$ na parte aérea de mudas de pinhão-manso sob omissão de nutrientes, em cultivo hidropônico

\begin{tabular}{lcccccc}
\hline Tratamento & $\mathbf{K}$ & $\mathbf{C a}$ & $\mathbf{M g}$ & $\mathbf{P}$ & $\mathbf{S}$ & N-total \\
\hline Completo & $40,9 \mathrm{~A}$ & $9,3 \mathrm{~A}$ & $12,4 \mathrm{C}$ & $2,3 \mathrm{C}$ & $1,0 \mathrm{~A}$ & $30,5 \mathrm{~A}$ \\
$-\mathrm{N}$ & $32,6 \mathrm{~B}$ & $7,2 \mathrm{~B}$ & $14,8 \mathrm{C}$ & $3,2 \mathrm{~B}$ & $0,9 \mathrm{~A}$ & $11,6 \mathrm{~B}$ \\
$-\mathrm{P}$ & $25,6 \mathrm{C}$ & $7,5 \mathrm{~B}$ & $10,9 \mathrm{C}$ & $1,1 \mathrm{D}$ & $0,6 \mathrm{~B}$ & $18,6 \mathrm{~B}$ \\
$-\mathrm{K}$ & $9,6 \mathrm{C}$ & $9,6 \mathrm{~A}$ & $21,2 \mathrm{~A}$ & $5,4 \mathrm{~A}$ & $1,2 \mathrm{~A}$ & $32,9 \mathrm{~A}$ \\
$-\mathrm{Ca}$ & $30,9 \mathrm{~B}$ & $6,3 \mathrm{~B}$ & $16,2 \mathrm{~B}$ & $2,7 \mathrm{~B}$ & $1,1 \mathrm{~A}$ & $27,5 \mathrm{~A}$ \\
$-\mathrm{Mg}$ & $44,9 \mathrm{~A}$ & $9,8 \mathrm{~A}$ & $7,5 \mathrm{D}$ & $3,5 \mathrm{~B}$ & $1,0 \mathrm{~A}$ & $29,0 \mathrm{~A}$ \\
$-\mathrm{S}$ & $38,9 \mathrm{~A}$ & $9,2 \mathrm{~A}$ & $10,3 \mathrm{D}$ & $3,7 \mathrm{~B}$ & $0,5 \mathrm{~B}$ & $31,0 \mathrm{~A}$ \\
$-\mathrm{B}$ & $38,9 \mathrm{~A}$ & $8,9 \mathrm{~A}$ & $12,8 \mathrm{C}$ & $2,3 \mathrm{C}$ & $0,8 \mathrm{~B}$ & $29,8 \mathrm{~A}$ \\
$-\mathrm{Cu}$ & $42,7 \mathrm{~A}$ & $7,6 \mathrm{~B}$ & $11,6 \mathrm{C}$ & $2,5 \mathrm{C}$ & $1,0 \mathrm{~A}$ & $32,2 \mathrm{~A}$ \\
$-\mathrm{Mn}$ & $46,8 \mathrm{~A}$ & $7,9 \mathrm{~B}$ & $12,6 \mathrm{C}$ & $3,1 \mathrm{~B}$ & $0,9 \mathrm{~A}$ & $33,2 \mathrm{~A}$ \\
$-\mathrm{Mo}$ & $35,6 \mathrm{~B}$ & $9,4 \mathrm{~A}$ & $13,4 \mathrm{C}$ & $2,7 \mathrm{~B}$ & $1,2 \mathrm{~A}$ & $32,9 \mathrm{~A}$ \\
$-\mathrm{Zn}$ & $35,6 \mathrm{~B}$ & $9,1 \mathrm{~A}$ & $14,4 \mathrm{C}$ & $2,9 \mathrm{~B}$ & $0,8 \mathrm{~A}$ & $33,1 \mathrm{~A}$ \\
$-\mathrm{Fe}$ & $43,6 \mathrm{~A}$ & $8,7 \mathrm{~A}$ & $12,2 \mathrm{C}$ & $2,4 \mathrm{C}$ & $1,0 \mathrm{~A}$ & $30,3 \mathrm{~A}$ \\
\hline
\end{tabular}

Médias seguidas de mesma letra na coluna não diferem entre si pelo teste Scott-Knott a 5\% de probabilidade. 
O Fósforo é muito requerido pelas plantas (Lin et al., 2013). Sua ausência limita o crescimento, por fazer parte de moléculas-chave do metabolismo celular, como ATP e ácidos nucleicos, (George et al., 1995). Lima et al. (2011b) estudaram o efeito de doses de $\mathrm{P}$ na produção de mudas de pinhão manso e observaram que, em plantas de 30 dias de idade, o aumento da dose de fósforo disponibilizada às plantas resultou em concentrações foliares aumentadas de $\mathrm{N}$, $\mathrm{K}, \mathrm{Mg}$ e $\mathrm{S}$, o que atribuíram ao efeito do $\mathrm{P}$ na produção de raízes e ao seu papel na absorção de íons, por via do consumo de ATP. Essas observações corroboram o encontrado neste estudo, em que a omissão de $\mathrm{P}$ determinou a redução das concentrações de $\mathrm{K}, \mathrm{Ca}$, S e N da parte aérea das plantas. Vichiato et al., (2009), trabalhando com a interação fósforo-magnésio, em mudas de mamoeiro, relatam que o estado nutricional de fósforo na planta pode alterar a absorção de outros nutrientes.

A omissão de fósforo causou redução de tamanho e número de folhas de pinhão-manso, mas não alterou a coloração das folhas, cujo valor de índice SPAD foi semelhante ao observado nas plantas do tratamento completo. O sistema radicular teve seu comprimento e volu- me bastante reduzidos (Figuras 1 e 2). De maneira geral, os sintomas de deficiência de fósforo são mais brandos do que os de nitrogênio e potássio (Raij, 1991), porém, Silva et al. (2009) a partir dos 40 dias da aplicação do tratamento de omissão de $\mathrm{P}$, em plantas de pinhão-manso, observaram o aparecimento de coloração arroxeada nos bordos e na parte abaxial das folhas mais velhas que evoluiu para necrose.

\section{Omissão de cálcio}

O tratamento com omissão de cálcio reduziu, significativamente, área foliar, número de folhas e massa de matéria seca de folhas; comprimento e massa de matéria seca do caule; comprimento, volume e massa de matéria seca das raízes (Tabelas1 e 2). Volume radicular, área foliar e produção de massa de matéria seca de raízes foram as características biométricas mais afetadas pela omissão de $\mathrm{Ca}$, com reduções de 64, 62 e 57\%, comparativamente às das plantas do tratamento completo. $\mathrm{O}$ teor de Ca na matéria seca da parte aérea das plantas do tratamento completo foi de $9,4 \mathrm{~g} \mathrm{~kg}^{-1}$. Com a omissão do elemento, houve redução significativa em sua concentração, que passou a $6,4 \mathrm{~g} \mathrm{~kg}^{-1}$. Com a omissão de Ca, houve redução do teor de $\mathrm{K}$, enquanto os teores de

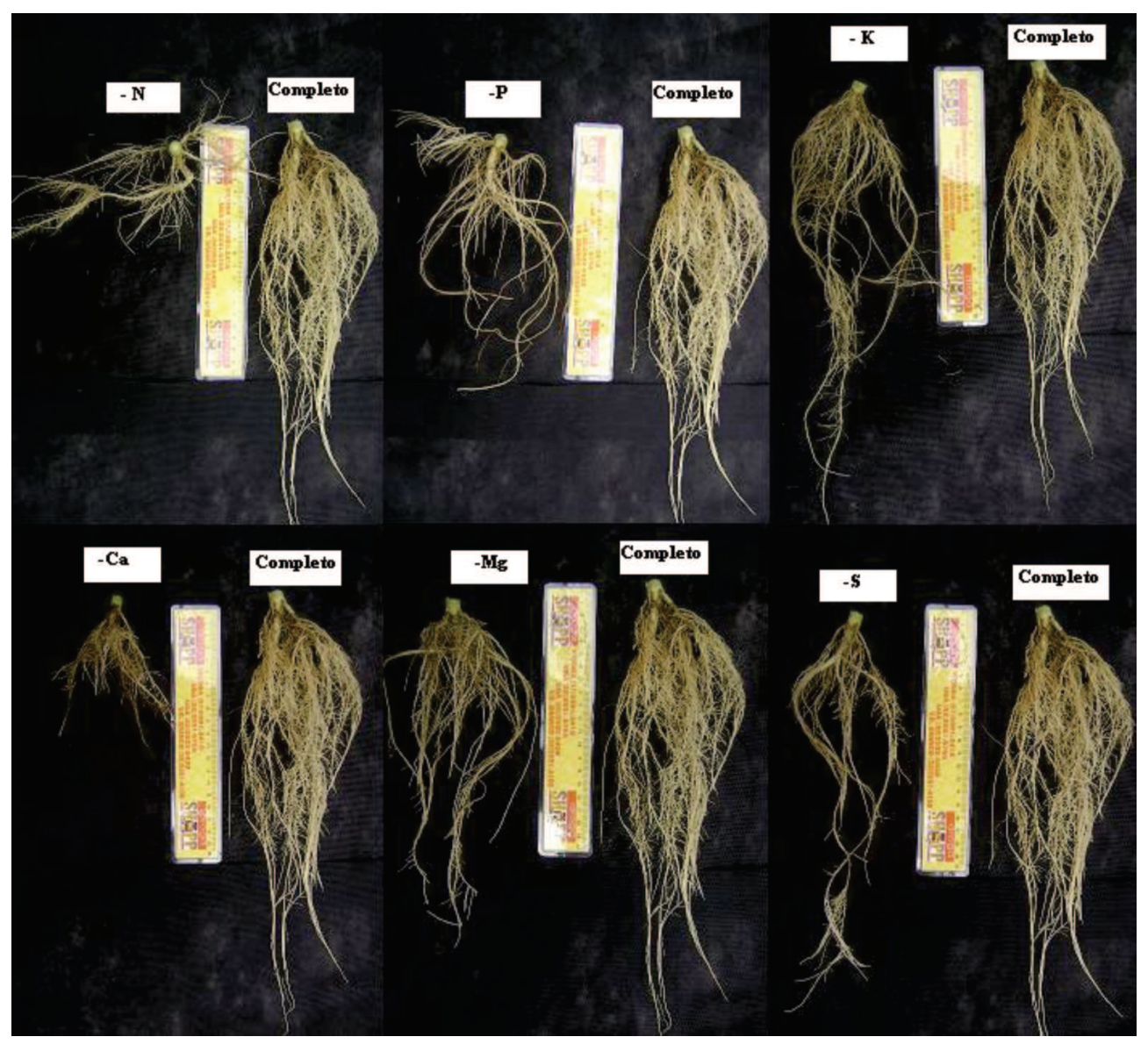

Figura 2. Sintomas visuais de deficiência de macronutrientes em raízes de mudas de pinhão-manso.

Rev. Ceres, Viçosa, v. 61, n.5, p. 723-731, set/out, 2014 
magnésio e fósforo sofreram efeito de concentração e elevaram-se (Tabela 3).

Cálcio é um macronutriente essencial para as plantas (Funk et al., 2013), desempenhando a importante função de estabilização da parede celular (White \& Broadley, 2003). Sua omissão reduz o crescimento e desenvolvimento de plantas como milheto (Pennisetum tiphoideum Stapf et Hubb. - Prado \& Vidal, 2008), tomate (Lycopersicon esculentum Mill. - Freitas et al., 2012) e orégano (Origanum vulgare L. - Dordas, 2009).

Na ausência de cálcio, foram observados encarquilhamento e necrose das folhas mais novas, comprometimento e morte da gema apical, paralisação da emissão de raízes novas e apodrecimento das secundárias (Figuras 1 e 2). Segundo Marschner (2012), a deficiência de Ca pode retardar o crescimento e causar a morte dos meristemas. Os resultados obtidos concordam com os de Silva et al. (2009) com pinhão-manso e com os de Lavres Junior et al. (2009) com mamoneira cultivar Íris.

\section{Omissão de micronutrientes}

As omissões de micronutrientes não resultaram em efeitos tão acentuados, quanto as de macronutrientes, sobre as características biométricas avaliadas. Cabe des- tacar o Zn, cuja omissão afetou, significativamente, comprimento e matéria seca de caules, número de folhas e produção de massa de matéria seca de raízes, e a do boro, que restringiu, significativamente, número de folhas, volume radicular e produção de massa de matéria seca de raízes. A omissão de Fe afetou a produção de massa de

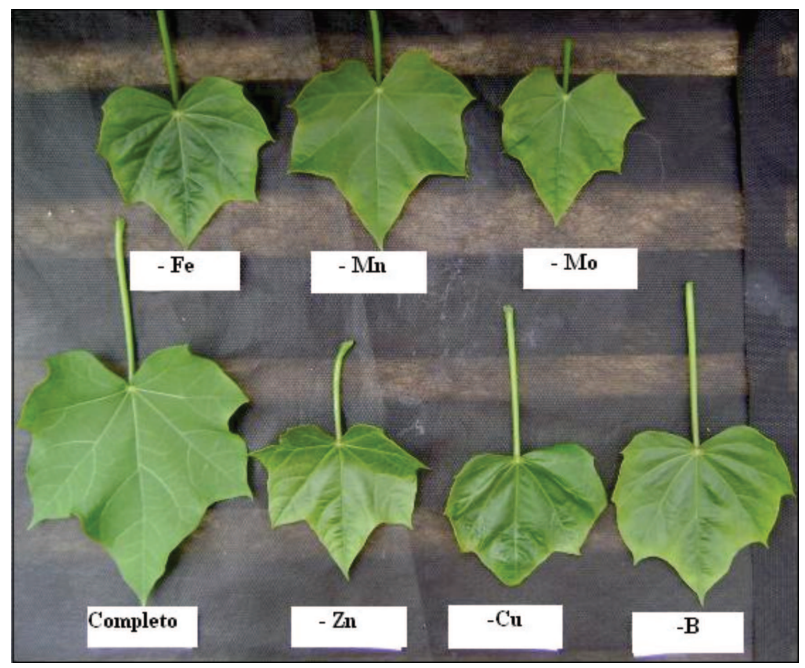

Figura 3. Sintomas visuais de deficiência de micronutrientes em folhas de mudas de pinhão-manso.

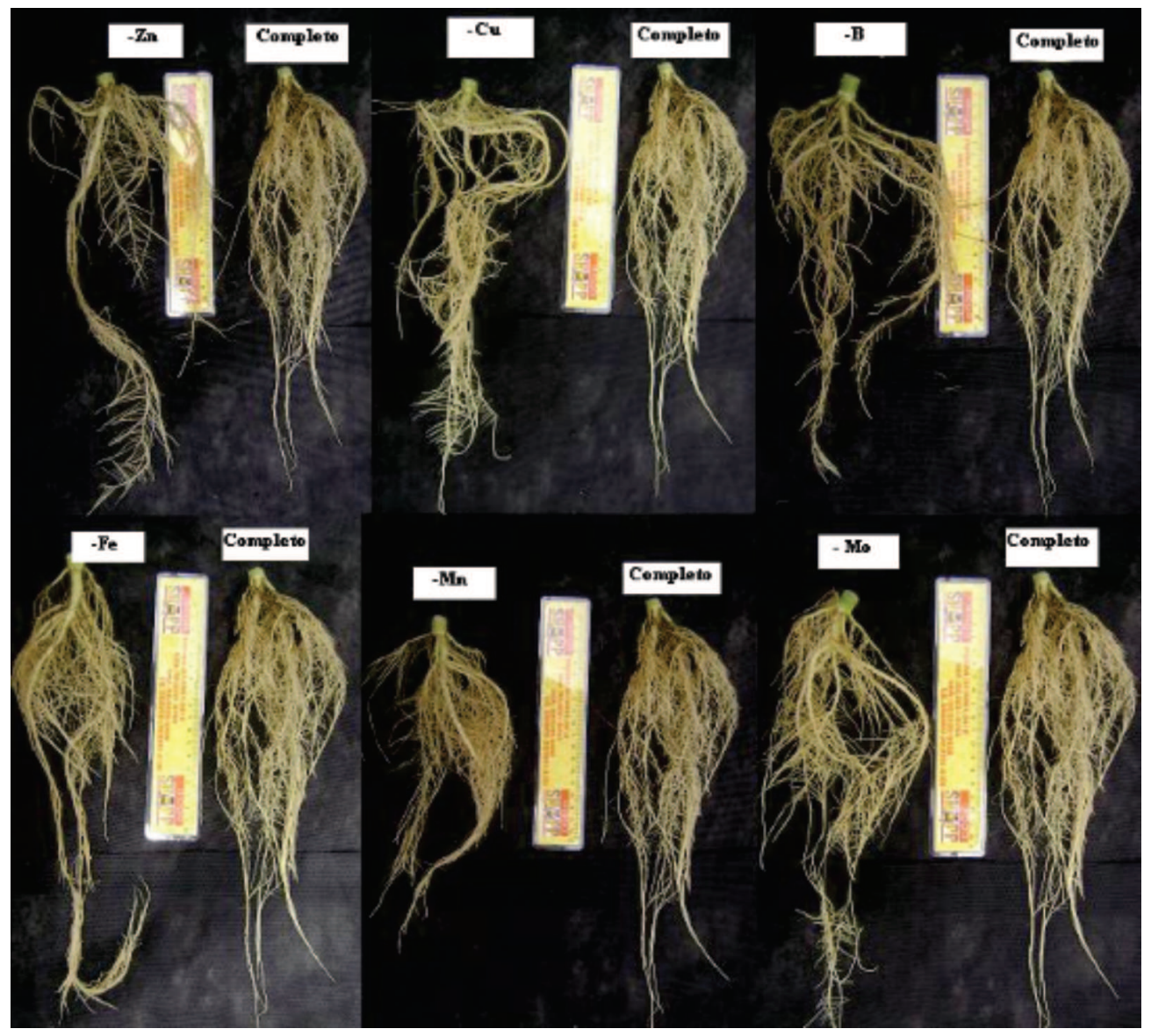

Figura 4. Sintomas visuais de deficiência de micronutrientes em raízes de mudas de pinhão-manso. 
matéria seca de raízes e, a de $\mathrm{Mn}$, o comprimento do sistema radicular. (Tabelas 1e 2). Quanto às concentrações dos macronutrientes, as omissões de molibdênio e de zinco reduziram os teores de potássio da parte aérea e as de cobre e manganês reduziram o teor de cálcio. $\mathrm{O}$ teor de fósforo aumentou pelas omissões de manganês, molibdênio e zinco e o de enxofre reduziu-se, significativamente, pela omissão de boro (Tabela 3).

O boro tem como função fisiológica a formação de ligações cis-diol na parede celular (O'Neill et al., 1996). Assim, a deficiência deste elemento inibe ou paralisa o crescimento dos tecidos meristemáticos das folhas e raízes, por interromper a divisão celular (Wimmer \& Eichert, 2013). O zinco atua como ativador enzimático, sendo responsável pela maturação e crescimento das plantas, e as alterações morfológicas causadas por sua deficiência são evidentes, principalmente, nas regiões mais jovens das plantas (Vitti \& Serrano, 2007). Corroborando os resultados aqui observados, este micronutriente foi o mais limitante para mudas de pinhão manso cultivadas em Neossolo Quartzarênico (Tanure, 2010).

Nos tratamentos com omissão de Zn, observou-se clorose internerval e encarquilhamento de folhas novas para cima (Figura 3), concordando com os resultados de Silva et al. (2009). Foi observada também ligeira redução do volume radicular (Figura 4).

As plantas sob deficiência de B apresentaram folhas novas encurvadas, deformadas e espessas, de forma que o limbo tornou-se mais arredondado (Figura 3). Em mamoneira (Lange et al., 2005) e em pinhão-manso (Silva et al., 2009) os sintomas foram semelhantes.

No tratamento com omissão de $\mathrm{Fe}$, ocorreu clorose internerval de folhas novas, com nervuras de coloração verde-escura (Figura 3). Em mamoneira (Lavres Junior et al., 2009) e em pinhão-manso (Silva et al., 2009), os resultados foram semelhantes. De modo geral, neste trabalho, as raízes não demonstraram sintomas de deficiência.

As plantas cultivadas com omissão de Mn apresentaram leve clorose internerval e início de encarquilhamento das folhas para cima (Figura 3), concordando com os resultados de Silva et al. (2009). Observou-se um pequeno comprometimento do sistema radicular (Figura 4).

Com a omissão de $\mathrm{Cu}$, as folhas novas apresentaram leve clorose internerval, encarquilhamento, com ocorrência de início de necrose nas margens (Figura 3). Esses resultados concordam com os encontrados por Silva et al. (2009).

Com omissão de Mo, observou-se início de clorose interneval e encurtamento dos bordos foliares, sendo que as raízes não apresentaram alteração (Figuras 3 e 4). Em mamoneira, não foram observados sintomas visuais de deficiência desse elemento (Lange et al., 2005).

\section{CONCLUSÕES}

O desenvolvimento das plantas de pinhão-manso foi mais comprometido pela deficiência dos macronutrientes, justificado pelas reduções da matéria seca de raiz, caule e folhas.

A ordem de restrição do crescimento provocada pela omissão de nutrientes foi: $\mathrm{N}>\mathrm{Mg}>\mathrm{S}>\mathrm{K}>\mathrm{Ca}=\mathrm{P}>$ $\mathrm{Zn}>\mathrm{B}=\mathrm{Fe}$.

As omissões de $\mathrm{N}$ e $\mathrm{P}$ foram as que mais afetaram os teores dos macronutrientes na parte aérea das plantas de pinhão-manso, sendo que plantas cultivadas em solução completa apresentaram 40,9; 9,38; 0,23 e 30,5 $\mathrm{g} \mathrm{kg}^{-1}$ de $\mathrm{K}, \mathrm{Ca}, \mathrm{P}$ e N, respectivamente, enquanto plantas cultivadas em solução com omissão de $\mathrm{N}$ apresentaram 32,6; 7,29; 3,2 e 11,6 $\mathrm{g} \mathrm{kg}^{-1}$ de $\mathrm{K}, \mathrm{Ca}, \mathrm{P}$ e N, e as submetidas à omissão de P 25,6; 7,51; 1,1 e 18,6 $\mathrm{g} \mathrm{kg}^{-1}$ de K, Ca, P e $\mathrm{N}$, respectivamente.

Nas folhas, as omissões de $\mathrm{N}$ e de $\mathrm{S}$ promoveram clorose uniforme das lâminas foliares, iniciando-se os sintomas nas mais velhas no caso do N, e nas mais novas, no caso do S. Folhas de plantas deficientes em $\mathrm{Mg}$, $\mathrm{Zn}, \mathrm{Fe}$ e Mo apresentaram clorose internerval, iniciando-se os sintomas nas mais velhas, no caso do $\mathrm{Mg}$, e nas mais novas, nos casos de $\mathrm{Fe}$ e $\mathrm{Zn}$. As omissões de K, $\mathrm{Mn}, \mathrm{Cu}$ e B resultaram em clorose dos bordos, mais acentuada nas folhas mais novas, no caso do $\mathrm{B}$ e nas mais velhas, no caso do $\mathrm{K}$. As omissões de $\mathrm{Ca}$, B e $\mathrm{Cu}$ promoveram deformidade das folhas.

\section{REFERÊNCIAS}

AOAC (1975) Official methods of analysis. 12 $2^{\mathrm{a}}$ ed. Washington DC, Association of Official Analytical Chemists. 1094 p.

Barroso DG, Figueiredo FAMM, Pereira RC, Mendonça AVR \& Silva LC (2005) Diagnóstico de deficiências de macronutrientes em mudas de teca. Revista Árvore, 29:671-679.

Biswas S, Kaushik N \& Srikanth G (2006) Biodiesel: technology and business opportunities - an insight. In: Biodiesel Conference Toward Energy Independance - Focus of Jatropha, New Delhi. Proceedings, Technology Information, Forecasting and Assessment Council/ TIFAC. p.303-330.

Braccini MCL, Braccini AL \& Martinez HEP (1999) Critérios para renovação ou manutenção de solução nutritiva em cultivo hidropônico. Semina: Ciências Agrárias, 20:48-58.

Braga JM (1983) Avaliação da fertilidade do solo: ensaios de campo.Viçosa, Imprensa Universitária/UFV. 101p.

Cakmak I \& Kirkby EA (2008) Role of magnesium in carbon partitioning and alleviating photooxidative damage. Physiologia Plantarum, 133:692-704.

Cakmak I (2013) Magnesium in crop production, food quality and human health. Plant and Soil, 368:01-04.

Camargo R, Maldonado ACD, Dias PAS, Souza MF \& França MS (2013) Diagnose foliar em mudas de pinhão manso (Jatropha curcas L.) produzidas com biossolido. Revista Brasileira de Engenharia Agrícola e Ambiental, 17:283-290. 
Coelho FS, Fontes PCR, Puiatti M, Neves JCL \& Silva MCC (2010) Dose de nitrogênio associada à produtividade de batata e índices do estado de nitrogênio na folha. Revista Brasileira de Ciência do Solo, 34:1175-1183.

Cruz CRP, Carvalho JEB, Souza-Filho LFS \& Queiroz DC (2007) Níveis de nitrogênio e a taxa fotossintética do mamoeiro "golden". Ciência Rural, 37:64-71.

Dordas C (2009) Foliar application of calcium and magnesium improves growth, yield, and essential oil yield of oregano (Origanum vulgares ssp. hirtum). Industrial Crops and Products, 29:599-608.

Epstein E \& Bloom AJ (2004) Mineral Nutrition of Plants: Principles and Perspectives. $2^{\text {nd }}$ ed. Sunderland, Sinauer Associates.400p.

Evans JR (1989) Photosynthesis and nitrogen relationship in leaves of C3 plants. Oecologia, 78:09-19.

Funk JL \& Amatangelo KL (2013) Physiological mechanisms drive differing foliar calcium content in ferns and angiosperms. Oecologia, 173:23-32.

George E, Marschner H \& Jakobsen I (1995) Role of arbuscular mycorrhizal fungi in uptake of phosphorus and nitrogen from soil. Critical Reviews in Biotechnology, 15:257-270.

Ginwal HS, Phartyal SS, Rawat PS \& Srivastava RL (2005) Seed source variation in morphology, germination and seedling growth of Jatropha curcas Linn. in Central India. Silvae Genetica, 54:76-80.

Guha S \& Rao IS (2012) Nitric oxide promoted rhizome induction in Cymbidium shoot buds under magnesium deficiency. Biologia Plantarum, 56:227-236.

Lange A, Martines AM, Silva MAC, Sorreano MCM, Cabral CP \& Malavolta E (2005) Efeito de deficiência de micronutrientes no estado nutricional da mamoneira cultivar Íris. Pesquisa Agropecuária Brasileira, 40:61-67.

Laviola BG \& Dias LAS (2008) Teor e acúmulo de nutrientes em folhas e frutos de pinhão manso. Revista Brasileira de Ciência do Solo, 32:1969-1975.

Lavres Junior J, Boaretto RM, Silva MLS, Correia D, Cabral CP \& Malavolta E (2009) Deficiências de macronutrientes no crescimento e na produção da mamoneira cultivar Íris. Revista Brasileira de Ciências Agrárias, 4:405-413.

Li SX, Wang ZH \& Stewart BA (2013) Responses of Crop Plants to Ammonium and Nitrate N. Advances in Agronomy, 118:205-397.

Lima RLS, Severino L, Cazetta JO, Azevedo CAV, Sofiatti V, Arriel NHC (2011a) Redistribuição de nutrientes em folhas de pinhão-manso entre estádios fenológicos. Revista Brasileira de Engenharia Agrícola e Ambiental, 15:1175-1179.

Lima RLS, Severino L, Gheyi HR, Sofiatti V, Arriel NHC (2011b) Efeito da adubação fosfatada sobre o crescimento e teor de macronutrientes de mudas de pinhão manso. Revista Ciência Agronômica, 42:950-956.

Lin HJ, Gao J, Zhang ZM, Shen YO, Lan H, Liu L, Zhao MJ, Zhou SF, Zhang YZ, Gao SB \& Pan GT (2013) Transcriptional responses of maize seedling root to phosphorus starvation. Molecular Biology Reports, 40:5359-5379.

Malavolta E (1980) Elementos de nutrição mineral de plantas. São Paulo, Editora Agronômica Ceres. 251p.

Malavolta E, Vitti GC \& Oliveira AS (1997) Avaliação do estado nutricional das plantas: princípios e aplicações. $2^{\mathrm{a}}$ ed. Piracicaba, Associação Brasileira para a Pesquisa da Potassa e do Fosfato. 319p.

Marschner P (2012) Marchner's mineral nutrition of higher plants. $3^{\text {rd }}$ ed. New York, Academic Press. 651p.

Niu J, Zhang W, Ru S, Chen X, Xiao K, Zhang X, Assaraf M, Imas P, Magen H \& Zhang F (2013) Effects of potassium fertilization on winter wheat under different production practices in the North China Plain. Field Crops Research, 140:69-76.
O’Neill MA, Warrenfeltz D, Kates K, Pellerin P, Doco T, Darvill AG \& Albersheim P (1996) Rhamnogalacturonan II, a pectic polysaccharide in the walls of growing plant cells, forms a dimer that is covalently cross-linked by a borate ester. Journal of Biological Chemistry, 271:22923-22930.

Padilla VM (2007) Microbial inoculant for growth and development of Physic nut (Jatropha curcas L.). In: $5^{\text {th }}$ Asia-Pacific Biotechnology Congress, Tagbilaran. Procedings, Philippine Society for Microbiology. p.33.

Pettigrew WT (2008) Potassium influences on yield and quality production for maize, wheat, soybean and cotton. Physiologia Plantarum, 133: 670-681.

Prado RM \& Vidal AA (2008) Efeitos da omissão de macronutrientes em solução nutritiva sobre o crescimento e a nutrição do milheto. Pesquisa Agropecuária tropical, 38:208-214.

Quintiliano AA, Deperon Junior MA, Avelar RC, Junco BB, Araújo JC, Fraga AC \& Castro Neto P (2006) Avaliação do teor de óleo de pinhãomanso extraído em lotes de baixa qualidade física. In: $3^{\circ}$ Congresso Brasileiro de Plantas Oleaginosas. Óleos, Gorduras e Biodiesel, Varginha. Anais, UFLA. 1242p.

Raij B van (1991) Fertilidade do solo e adubação. Piracicaba, Editora Agronômica Ceres. 343p.

Resh H (2013) Hydroponic Food Production, $7^{\text {th }}$ ed. New York, CRC Press. 524p.

Schadchina TM \& Dmitrieva VV (1995) Leaf chlorophyll content as a possible diagnostic mean for the evaluation of plant nitrogen uptake from the soil. Journal of Plant Nutrition, 18:1427-1437.

Silva EB, Tanure LPP, Santos SR \& Rezende Júnior PS (2009) Sintomas visuais de deficiências nutricionais em pinhão-manso. Pesquisa Agropecuária Brasileira, 44:392-397.

Singh RA, Kumar M \& Haider E (2007) Synergistic cropping of summer groundnut with Jatropha curcas - A new two-tier cropping system for Uttar Pradesh. Journal of SAT Agricultural Research, 5:1-2.

Souza SR \& Fernandes MS (2006) Nitrogênio. In: Fernandes MS (Ed.) Nutrição mineral de plantas. Viçosa, Sociedade Brasileira de Ciência do Solo. p.215-252.

Tanure LPP (2010) Avaliação das limitações nutricionais em mudas de pinhão-manso cultivadas em casa de vegetação. Dissertação de Mestrado. Universidade Federal dos Vales do Jequitinhonha e Mucuri, Diamantina. 76p.

Vichiato M, Carvalho JG, Vichiato MRM \& Silva CRR (2009) Interações fósforo-magnésio em mudas de mamoeiros Tainung $\mathrm{n}^{\circ} .1$ e Improved Sunrise Solo 72/12. Ciência Agrotécnica, 33:1265-1271.

Vitti GC \& Serrano CGE (2007) O zinco na agricultura. DBO Agrotecnologia, 3:10-11.

White PJ \&Broadley MR (2003) Calcium in plants. Annals of Botany, 92:487-511.

Wimmer MA \&Eichert T (2013) Review: Mechanisms for boron deficiency-mediated changes in plant water relations. Plant Science, 203-204:25-32.

Yang LT, Yang GH, You X, Zhou CP, Lu YB 7 Chen LS (2013) Magnesium deficiency-induced changes in organic acid metabolism of Citrus sinensis roots and leaves. Biologia Plantarum, 3:481-486. 